\title{
THE DIMENSIONALITY OF POLITICAL SPACE: EPISTEMOLOGICAL AND METHODOLOGICAL CONSIDERATIONS *
}

\author{
Kenneth Benoit and Michael Laver
}

10 February 2011

\begin{abstract}
Spatial characterizations of agents' preferences lie at the heart of many theories of political competition. These give rise to explicitly dimensional interpretations. Parties define and differentiate themselves in terms of substantive policy issues, and the configuration of such issues that is required for a good description of political competition affects how we think substantively about the underlying political space in which parties compete. For this reason a great deal of activity in political science consists of estimating such configurations in particular real settings. We focus on three main issues in this paper. First, we discuss the nature of political differences and from this construct an interpretation of the dimensionality of the political space needed to describe a given real setting, underscoring the essentially metaphorical and instrumental use of this concept. Second, we contrast ex ante and ex post interpretations of this dimensionality. Third, we illustrate potential hazards arising from the purely inductive estimation of political spaces using a spatial example from the physical world and political competition in the EU Parliament as a political example.
\end{abstract}

Key Words: Policy dimensions, party competition, policy positions, ideal point estimation, expert surveys.

\footnotetext{
* Author contact information: Kenneth Benoit, Methodology Institute, London School of Economics, kbenoit@1se.ac.uk; Michael Laver, Department of Political Science, New York University, michael.laver@nyu.edu.
} 
Discussion of political competition almost invariably uses the language of space, direction and distance. It is for all intents and purposes impossible to describe political preferences without referring to "positions", "stances" or "orientations". We discuss policy-based political competition by referring to agents' "positions" and "movement" on key issues. We describe positions and movements, explicitly or implicitly, in terms of underlying conceptual spaces which may or may not "really" exist. These spaces are spanned, explicitly or implicitly, by "dimensions" that allow us to give substantively meaningful interpretations to position and movement. We are so accustomed to this language that it has become intrinsic to our thinking about political competition. This not just a key part of the lexicon of professional political scientists, it is deeply ingrained in the everyday political discourse of ordinary decent civilians. Despite the ubiquitous use of spatial language to describe political competition, however, the attribution of spatial characteristics to policy differences is essentially metaphor: "understanding and experiencing one kind of thing or experience in terms of another" (Lakoff and Johnson 1980, 455). Our entire lexical and conceptual apparatus for thinking about political competition, therefore, is fundamentally grounded in a physical analog to a concept that - unlike real spaces we can never physically observe or objectively measure.

The most familiar political metaphor belongs to a class of extremely pervasive metaphors that Lakoff and Johnson $(1980,461)$ term “orientational”. Dating from the era of the French Revolution (Carlyle 1871, 192), this is the well-known "left-right" political dimension, contrasting a more protectionist state with socially liberal values on one hand with a more conservative social vision and more laissez-faire economics on the other. Even this drastically oversimplified version of the "left-right dimension", however, refers to two potentially separable issues: one about economic 
policy and a second about the state regulation of social behavior. Indeed it is extremely common to need more than a single dimension to characterize key political differences, even though we are typically much less certain about the number and substance of additional dimensions that might be needed. Researchers who set out to "measure" and "map" policy spaces characterizing real-world political competition continually confront this uncertainty. A good example which highlights the problems of applying the spatial metaphor can be found in studies of the relatively new phenomenon of transnational European party competition. ${ }^{1}$ The challenges are described starkly by Gabel and Hix $(2004,93)$ :

Scholars of EU policy-making have adopted conflicting assumptions about the dimensionality and character of the EU policy space. Since the shape of the political space - the number of dimensions, the policy content of these dimensions, and the location of actors in this space - is a central determinant of political competition and outcomes, these conflicting assumptions often lead to different conclusions about and interpretations of EU policy-making. This is a series impediment to our advancing our theoretical understanding of EU politics. A resolution of this theoretical conflict depends on assessing the relative value of the conflicting assumptions.

This challenge illustrates our core task in this paper, which is to elaborate and review some of the core epistemological and methodological issues that arise from any attempt to measure the dimensionality of any given political space. We contrast two basic approaches to this problem. The first is an a priori approach whereby key dimensions are specified ex ante, in advance of measurement. The second is an ex post inductive approach in which key dimensions are estimated a posteriori as latent constructs that can be derived from some set of measurements that have already been made. With the a priori approach, the key methodological challenge is to identify and justify the number and substance of a set of dimensions specified in advance of any

\footnotetext{
${ }^{1}$ While especially common in EU studies (e.g. Pennings 2002; Marks and Steenbergen 2002; Selck 2004; McElroy and Benoit 2007), the "mapping spaces" approach has been widely used in other contexts (e.g. Benoit and Laver 2006 Ch 6; Warwick 2002).
} 
empirical research in which observations are to be collected. With the a posteriori approach, the challenge is just the opposite: to interpret the number and substance of latent dimensions inferred from inductive analyses of a set of observations that have already been made. Whichever approach is used, the key epistemological challenge is the same. The "spaces" of interest are ultimately metaphors and both the dimensions spanning these spaces and agents' positions on these dimensions are fundamentally unobservable. No matter how sophisticated our methodological tools, we ultimately lack the means to verify that we have "correctly" characterized a political space and "accurately" located the actors within it, because these are not only unobservable but remain metaphorical, not physical, spatial objects.

In what follows, we begin by bringing parts of the methodological arsenal of modern political since to bear upon a "real" physical space which we feel confident really does exist, the London Underground railway system. We do this to help us understand pitfalls that await us when we set out to use the same methodological arsenal to estimate metaphorical and/or conceptual political spaces. We move on to explore these same pitfalls as they arise when we try to estimate the "positions" of agents in the "policy spaces" that are part of the bread and butter of modern political science, using the specific example of estimating the positions of the party groups in the European Parliament. Before we do any of this, we dig a little deeper into what we have in mind when we talk about political "spaces" and policy "dimensions".

\section{FROM DIFFERENCES IN PREFERENCES TO POLICY DIMENSIONS}

Different agents may have different preferences. Consequent perceptions of similarity and difference are naturally expressed in terms of distances. Think of Jack, Jill and Joe-Bob. Are Jill's preferences more like Jack's, or Joe-Bob's? We can also ask, 
meaning the same thing, are Jill's preferences closer to Jack's than to Joe-Bob's? In doing this, we describe Jill's perceptions of similarities and difference in terms of distances. We can aggregate perceived similarities and differences in the preferences of agents who interest us and organize these into a matrix of inter-agent distances, and it is this matrix that underlies any "spatial" representation of agents" preferences.

The notion of being able to perceive political dissimilarity and then describe this in terms of closeness and distance is more primitive than any discussion of spaces and dimensions. The standard utility function underlying most choice models in political science, for instance, involves aggregating Euclidean distances between alternatives but does not actually require dimensional representations these distances (Adams et al. 2005; Austen-Smith and Banks 2000, 2005; Schofield 2008). Given a matrix of distances, however, and a desire to make substantive sense of these, it is a straightforward matter to go one step further and scale the distances, going on to describe agents' positions in terms of some underlying conceptual space (Gärdenfors 2000). As a methodological matter, furthermore, the estimation of the underlying distance matrix may be based on some aggregation of agents' scores on particular substantively meaningful scales, for example survey responses to batteries of attitude questions. Meaningful substantive interpretation of the matrix of inter-agent distances, or the conceptual space that can be derived from these, requires us to talk in terms of substantive "dimensions" that span the space.

Similarities and differences in the preferences of agents on a domain of matters such as legalizing abortion, marijuana or same-sex marriage, for example, can be described and analyzed in terms of a "liberal-conservative" dimension that concerns the appropriate degree of public regulation of private social behavior. This dimension, furthermore, may have little or nothing to do with other matters that interest people, 
such as whether to regulate carbon emissions or join a single European currency. Just as the north-south and east-west dimensions allow us to interpret relative positions of points in a geographic space, we use substantive policy dimensions to interpret systematic patterns in the policy preferences of political agents who interest us.

When consider which particular substantive dimensions we might use to do this, we have natural recourse to a set of concepts that are part of the established terms of political discourse - which we use when we talk to each other about similarities and differences in people's political preferences. Engaged citizens who know nothing at all about political science, and care less, talk to each other in a meaningful way about candidate $\mathrm{X}$ being more liberal, or conservative, than candidate $\mathrm{Y}$. They expect to understand each other when they communicate using these terms and, as part of this mutual understanding, they feel able to draw inferences about the relative positions of candidates $\mathrm{X}$ and $\mathrm{Y}$ on matters such as legalizing abortion, marijuana or same-sex marriages. One simple interpretation of the "dimensionality" of a political space, therefore, concerns how many substantively relevant dimensions we need in order to say what we want to say about similarities and differences between agents who interest us. This is easy to say but hard to do, for two main reasons. First, we have no objective empirical criterion for what is "substantively relevant" given the problem at hand. Second, there are many different, and potentially contradictory, ways to determine "how many" dimensions is enough for any given purpose.

Thinking about what is and is not substantively relevant to the problem at hand, much of our work has already been done by generations of people who have talked about politics before us, in effect using their own informal models of politics to specify what is substantively important and what is not. Ultimately, this is an inductive process since political discourse is rather like a giant feral factor analysis. 
The concepts that emerge - liberal versus conservative, left versus right - emerge because people over the years have found them simple and effective ways to communicate their perceptions of similarity and difference. While in a strict sense these conceptual dimensions are not defined a priori for a state of nature, we may for all practical purposes take them as primitives that can be meaningfully used in our descriptions and analyses of politics in the place and time in which we live. The important point is that this exercise is conducted ex ante, before we engage in a particular piece of research. In this sense, these a priori dimensions of political similarity and difference are the building blocks of our research.

The second significant complication concerns the level of generality at which we specify dimensions of political difference. This in turn affects our answer to the question of "how many" dimensions of difference are relevant. The issues that confront us arise because: (a) other things equal we prefer parsimonious descriptions of the world to complicated ones; (b) there are in theory very many potential dimensions of difference between agents that might be politically relevant; (c) in practice, bundles of these dimensions are "correlated", in the sense that agents" positions on one dimension in some bundle can be reliably predicted from their positions on some other dimension in the same bundle. Thus, when talking above about a liberal-conservative dimension, we described this substantively in terms of a "domain of matters such as legalizing abortion, marijuana or same-sex marriage". Linguistically, this was a quick and effective way for us to use examples to show you what we have in mind when we talk about a liberal-conservative dimension. Conceptually, this trick works because of a general consensus that preferences on these three distinct matters are, empirically, closely correlated in the real word. 
Knowing someone's views on legalizing abortion and marijuana makes it easier to predict her views on same-sex marriage. In principle it need not, in practice it does.

More generally, knowing an agent's views on issues A, B and C, often allows us to make a good prediction of her unknown views on issue D. This allows us to treat observed preferences on some bundle of issues A, B, and C as if these were correlates of some unobserved latent dimension, $\boldsymbol{L}$ (Converse 1964). This is exactly what we did when we described agents' observed views on abortion, marijuana and same-sex marriage as if they all were related to an, unobserved, latent liberal-conservative dimension. We leave moot the question of whether the latent dimension "really" exists, whatever that means. We use it, as if it exists, as a device that helps us describe and analyze political competition. We are simplifying our description of the world in this case by using one general dimension of difference (liberal-conservative) to represent three more specific ones (abortion, marijuana and same-sex marriage). There is no "right" answer to the question of which of these alternative representations is better but, because we always prefer parsimony, we prefer the lower dimensional representation if this does not destroy too much information about the preferences of the set of agents who interest us.

To summarize our argument so far, there are many potential dimensions of political difference between any set of agents in which we might be interested. If we want to talk about these dimensions, we rely upon a tried and tested conceptual language that has evolved over generations, a set of conceptual dimensions that, as a matter of empirical practice, enable meaningful political discourse. Looking forward to the design of any given future research project, we can take these dimensions as de facto primitives. While there may be very many dimensions of difference between agents, in practice we observe that agents' preferences on bundles of these tend to be 
highly correlated. This allows us to summarize preferences in each bundle as if these were related to some underlying latent dimension, in turn allowing us to generate more parsimonious descriptions and analyses of political competition. All of this casts the question of dimensionality in relatively simple terms. How many latent dimensions of political difference do we need to describe and analyze the political problem at hand without destroying "too much" information?

Not surprisingly, this problem is much easier to ask than to answer. This is because the appropriate "dimensionality" of some political space depends on the political problem at hand. There is no general "dimensionality" that is applicable to any conceivable question regardless of context, but rather a range of possibilities that depend on which question we seek to answer. We illustrate this point with an example from the physical world, in which we may at least feel we are on solid ground.

\section{DESCRIPTIVE REPRESENTATIONS OF (PHYSICAL) SPACES}

If we "know" the metric of distance and have firm beliefs about the dimensionality of the spaces we are dealing with, then representing locations within this space is much more simple. Because metrics and distances are really only knowable in the physical world, we use an example of physical mapping as a source of insight into our ability to estimate and interpret spatial dimensions. As we will see, however, how we approach this apparently simple problem of mapping well-understood geographic locations, even in relation to something as apparently fundamental as how many dimensions we should use, is determined entirely by the purpose of the map.

\section{Physical descriptions using one dimension}

The way in which a given map reduces a wealth of potentially extraneous and confusing detail into a usable simple representation depends critically on the purpose 
for which the map is needed. Nowhere is this more apparent than for maps of transport systems. Many will be familiar with the iconic map of the London Underground (the "Tube") the current design of which first published in 1933 and can be traced to the engineering draughtsman Harry Beck. Simplifying the complex London underground in the manner of an electrical wiring diagram, Beck's new map sacrificed geographic accuracy for dramatically enhanced passenger usability. It showed relations between tube stations and interchanges between tube lines very clearly. It was immediately seized on by the public as a much more useful tool for planning journeys on the London underground railway system than the previous geographically accurate map. This was despite the fact it was little better than useless, and sometimes positively misleading, when navigating between tube stations at street level. Many other underground railway systems around the world subsequently copied this innovation. Thinking of the unprecedented success of London tube map as feral research project, we conclude that, despite its striking geographic inaccuracies, it is an excellent conceptual map of the London underground railway system.

\section{[FIGURE 1 ABOUT HERE]}

The top panel of Figure 1 shows a two-dimensional geographically accurate plot of the locations of Central Line stations on the London Underground. ${ }^{2}$ This shows the configuration of stations to be a somewhat rotated U-shape. Harry Beck's key psychological insight was that two dimensions are unnecessary to map the Central Line in a way that is useful for tube travellers, who need only the representation shown in the bottom panel of Figure 1. If the stations are ranked from west to east and plotted as a straight line, no information relevant to tube travellers is lost. In this particular case, the north-south axis, while conveying perfectly accurate

\footnotetext{
${ }^{2}$ Two small branch lines have been excluded. We also ignore that fact the stations are located in threedimensional physical space and some stations have higher elevations above sea level than others.
} 
information about station locations, is a distraction that conveys no information not already represented in the east-west axis. The physical locations are "twodimensional" in terms of their coordinates in physical space but, for transit from one point to the other using the underground railway system, the most useful representation has only one dimension. Just as it is for the one-dimensional denizens of "Lineland" in Edwin Abott's novel Flatland", the addition of a second dimension is irrelevant since travel can only occur between adjacent stations along the line, even if this is curved in a two-dimensional graphical space. A crow seeking the shortest route between the surfaces of the Epping and West Ruislip stations, however, would be seriously misled by the one-dimensional map. Likewise, a voracious earthworm trying to tunnel from Epping to Holborn, the latter a particularly deep station, also needs to know elevations from sea level - a third dimension we typically ignore when we simply ride the tube.

\section{Physical descriptions in two dimensions}

While a one-dimensional representation serves Central line passengers very well, we need look no further than the Circle line to find an otherwise equivalent example where a one-dimensional representation would serve passengers very poorly. The top panel of Figure 2 is a geographically accurate representation of Circle Line stations in two dimensions. ${ }^{4}$ This shows that the Circle line is very far from being a circle, but that is it is, topographically, a loop - a very important piece of information for London tube travellers to know. In stark contrast to the Central Line, if we plot Circle line stations on a single dimension the results are extraordinarily misleading. The bottom panel of Figure 2 shows one such plot, plotting locations of Circle Line stations on the east-west dimension. This shows St James Park and Euston Square

\footnotetext{
${ }^{3}$ Edwin Abbott, Flatland, New Ed ed. (New York: Dover Publications, 1992).

${ }^{4}$ The recently-opened Hammersmith Branch is excluded to simplify the presentation
} 
stations as being both adjacent to each other and very close together, for example, but any tube passenger who acted on this basis would be in for a very nasty shock. These two stations are about as far apart on the Circle Line as it is possible to be. Without belaboring the point, the "best" map of any underlying reality, and the best dimensionality for this map, depends sharply on what the map is for.

[FIGURE 2 ABOUT HERE]

\section{INDUCTIVE REPRESENTATIONS OF DIMENSIONALITY}

The issues raised in the previous section concern a setting for we have perfectly accurate observations of positions on the basis vectors (east-west, north-south in this case) in which we are interested. Typically in the social sciences, however, the basis vectors that concern us are latent dimensions that are fundamentally unobservable. The best we can do is to try and estimate agents' positions on these latent dimensions using their positions on observable components of these. While we cannot directly estimate agents' positions on a latent liberal-conservative dimension, for example, we can indirectly do this by collecting information on more explicit dimensions such as abortion, legalization of marijuana and same-sex marriage and use this information to estimate positions on the latent dimension that interests us. This is essentially an exercise in scaling and it is at this point that the distinction between a priori and inductive approach becomes critical.

\section{Estimating positions on a priori scales}

Returning to the London tube map, imagine we are interested in the geographic locations of the stations and know very well that a two-dimensional map with east- 
west and north-south dimensions as basis vectors is the best way to describe these. ${ }^{5}$ The "dimensionality" of the station space, and the substantive meaning of the dimensions, would not be left as a matter for empirical investigation but would be assumed a priori. Imagine furthermore that for some reason we cannot observe the positions of tube stations on these dimensions directly, but only have access to noisy indicators of these. Finally, imagine that we have good a priori reasons to believe that some of these noisy indicators are associated with the east-west dimension, and some with the north-south dimension. We are now in essence confronted with the problem of developing good unidimensional scales of east-west and north-south. A standard approach is to construct additive scales of these latent variables using our noisy indictors.

We simulate this problem by taking the true coordinates of the Circle Line stations, plotted in the top panel of Figure 2, and creating ten unbiased noisy indicators for each of the east-west ("easting") and the north-south ("northing") dimension. We do this for each indicator by adding a random disturbance term to the true value, drawn from a normal distribution with a mean of zero and a standard deviation equal to the range of observations for the "true" variable in question. We then construct additive scales of east-west and north-south by averaging values from their ten noisy indicator variables. Scale diagnostics arising from doing this, summarized in Table 1, would leave most social science researchers ecstatic, with Cronbach's alphas of 0.91 for each scale. The alpha values for individual noisy components, furthermore, are always less than or equal to the overall scale alpha, showing that scale reliability would not be improved by dropping any individual component. This is because the noise for each indicator, while substantial, is well

\footnotetext{
${ }^{5}$ How do we know this? We grew up from childhood observing adults successfully navigating the world using maps such as these.
} 
behaved, so that additive scaling functions exactly as it should. The bottom row of the table shows that the correlations of the additive scales with the "real" latent variable, which would be unknowable in any real application, are 0.97 and 0.96 , showing that this would have been a superbly effective exercise in a priori unidimensional scaling. This success has been achieved by leveraging our prior knowledge that there are two dimensions, that the latent variables are east-west and north-south, and that the respective sets of noisy indicator variables do indeed relate to these in some way.

\section{[TABLE 1 ABOUT HERE]}

The fruits of thus scaling exercise are plotted in Figure 3. The top panel plots a single noisy indicator of east-west against a single noisy indicator of north south. The results are horrible and very far from the "true" picture. The Circle Line is completely scrambled, though we would have had no way of knowing this has we had access to just a single noisy indicator for each latent variable. ${ }^{6}$ The bottom panel of Figure 5 plots the two additive scales against each other and, comparing this with Figure 2, we see something that looks much more like the "true" tube map. It has detailed inaccuracies arising from the noisy data, especially at the east end of the line where Figure 2 shows that stations are in fact very close together, but at least stations that should be on the west are on the west, those that should be on the east are on the east, and so on. In this sense the a priori scaling exercise has been a success.

\section{[FIGURE 3 ABOUT HERE]}

\section{Inductively estimating dimensionality and scale positions}

Now consider the situation that would arise if we made no a priori assumption about the number and substantive nature of the latent dimensions spanning the space we

\footnotetext{
${ }^{6}$ To get a sense of the scale of the noise, the easting indicator correlated 0.53 with the "true" easting, and the northing indicator correlated 0.68 with the true northing - correlations that we are accustomed to accepting in the social science as "not bad".
} 
wish to plot. The research task is now to use purely inductive methods to estimate both the dimensionality of the space and the substance of the latent dimensions spanning this. This is exactly what most of the "mapping the policy space" research designs in political science in fact try to do. They take a series of noisy indicators and use these either to scale the locations of agents inductively, or alternatively use data reduction methods to determine the number and content of the "latent dimensions" producing the indicators. ${ }^{7}$ Continuing with our London tube example, we can simulate inductive estimation by attempting to scale the two-dimensional representation from our noisy geographic variables (those in the first five rows of Table 1). Since in political applications we do not usually know exactly what the indicators should be and are conditioned to think generally that more information is superior to less - we also supplement the noisy geographic variables with data on five other characteristics of the Circle line stations, all related in some way to geography. The new variables concern: the date the station opened; the number of passengers who used the station in 2008; the number of platforms in the station; the fare charging zone; and, for the London borough in which the station is located, the percent of the population classified by the census as having Irish origins. Since we now have no a priori idea about the number or substantive content of the latent dimensions of the space we want to estimate, we have no a priori idea whether these five new indicator variables, or indeed any indicator variable in our set, might be helpful in producing this map. A commonly used way forward would be to identify latent dimensions using a technique such as factor analysis. Referring back to our description of latent dimensions in terms of bundles of particular salient policy issues on which agent's preferences are intercorrelated, we can specify the research task as seeking to identify these bundles in a

\footnotetext{
${ }^{7}$ Perhaps the ultimate example is Gabel and Huber (2000), who treat the entire Comparative Manifesto Project dataset (Budge et al 2001) as providing variables on 56 specific policy issues, and use factor analysis to reduce this to a one-dimensional solution they called "left-right".
} 
given empirical setting - leaving the number and content of the bundles as open questions.

The first task is to estimate the number of inter-correlated bundles in a given set of indicator variables that we take to describe the setting we wish to model. We can do this by estimating the number of orthogonal principle components satisfying some criterion, and this number can be interpreted as the "dimensionality" of this setting. A common method is to use a technique such as factor analysis to generate a "scree" plot of the eigenvalues of the common factors extracted from a set of indicator variables, plotting factor eigenvalues in descending order of variance explained. This downwards sloping plot may exhibit an "elbow" as the eigenvalues suddenly level off, implying that adding another latent dimension does not substantially increase the amount of explained variance in the set of indicator variables. This elbow can be used to infer inductively that the "best" low-dimensional representation of the set of indicator variables is $d$-dimensional, in the sense that using $d+1$ dimensions does not capture significantly more of the variance in the original high-dimensional space. An alternative inductive approach is to retain latent dimensions for which eigenvalues are greater than unity. Crudely speaking these are dimensions that contain more information that a typical dimension in the original high dimensional space. These two techniques can generate very different "empirical" estimates of dimensionality, especially when the original data space is high dimensional, in which case there may be many more latent dimensions with eigenvalues greater than unity than the number of dimensions indicated by the scree plot.

Figure 4 shows a scree plot of a factor analysis of the fifteen variables dealing with central line tube stations and shows that this is inconclusive. There is possibly an elbow after the first dimension, which would suggest a one-dimensional 
representation, but the plot has a smooth slope after this, at least until five dimensions are reached. On this account, the space of central line tube stations is either one- or five-dimensional. In contrast, the horizontal line in Figure 4 shows that the alternative test, keeping factors with eigenvalues greater than unity, implies four dimensions. No inductive method suggests the two dimensions of the "real" tube map we are trying to retrieve. A purely inductive approach does not help us determine the dimensionality of the space we want to plot in this case, at least not the sense that dimensionality can be inferred inductively from our data reduction analysis.

\section{[FIGURE 4 ABOUT HERE]}

However, if we have a priori information, over and above the dataset that we have collected, that the space we want to plot is two dimensional, then we are on firmer ground. Table 2 reports rotated factor loadings for a two-factor analysis of the fifteen variables measuring aspects of Central line Tube stations. Using a priori information that the solution we seek is two-dimensional, and the following the convention in principal components analysis of using variables with factor loadings over 0.5 to interpret the inductively derived latent variables $a$ posteriori, we would see that the first factor identified a bundle comprising all the east-west variables, and a second factor a bundle comprising all the north-south variables. The only nongeographic variable loading over 0.5 is the percent Irish in the borough, as it happens reflecting a demographic pattern that London-Irish tend to live in north London. Notwithstanding this empirical reality, attempting to interpret Table 2 by spinning some yarn about how "percent Irish" is a substantively meaningful component of geographic north-south leads us down tortured paths that will be painfully familiar to all who have been involved in the vigorous hand-waving often associated with post hoc interpretations of inductively derived "policy" dimensions. 


\section{[TABLE 2 ABOUT HERE]}

Just as Rovny and Marks (this special issue) found in their comparisons of different reductions of policy locations to determine the "dimensionality" of policy spaces, our representation of physical spaces as the two principal components from a set of indicator variables is heavily influenced by the choice of indicator variables. Unlike most forms of data analysis where more information always gets us closer to the answer, in dimensional analysis where our objective is to "map" unknown policy "spaces", our answers will depend entirely on the questions we ask in the form of what ingredients we believe provide information on the underlying dimensional configuration. This point was first explored by Weisberg (1974) but appears to have been largely ignored by most subsequent researchers.

Armed with results from factor analyses such as those reported in Table 2 and an a priori assumption about the dimensionality of the space described by a set of indicator variables, we can identify the substance of the latent dimensions inductively. We could then construct additive scales to measure agents' positions on these dimensions that combined the indicator variables identified in the factor analysis. Though in this case we would unwittingly do something a bit odd by including the London Irish, we would not go too far wrong and this scaling exercise is essentially the same as the one we report in Table 1.

An alternative approach is to use classical multidimensional scaling (MDS) to scale an inter-station distance matrix generated by the 15 indicator variables listed in Table 2. Once more in this case, however, this does not help us with an inductive estimate of dimensionality. Percentages of variance explained by different dimensions are as follows: $56,12,9,7,5,3,2 \ldots$. Forced to make a purely inductive estimate of dimensionality, we would infer that the space is one-dimensional. If we had good $a$ 
priori information that the space was indeed two-dimensional, we could use MDS to construct a two-dimensional plot based on all 15 indicator variables. This is shown in Figure 5 and does give a small amount of information about which stations are east and which are west but we would have no way inductively to know that this was the good information and the rest of the plot, frankly, bears little relation to the underlying "reality" it purports to represent. ${ }^{8}$ In effect, we would be terribly misled about the Circle line by this plot if we thought that its two dimensions represented something meaningful in relation to physical geography.

\section{[FIGURE 5 ABOUT HERE]}

The bottom line is that we have no good way to plot the Circle Line tube stations from a set of noisy and potentially irrelevant data unless we have some $a$ priori estimate of dimensionality. If we do however have an independent estimate of the "right" number of dimensions, then we can use techniques of dimensional analysis such as factor analysis to identify bundles of inter-correlated variables that both help us interpret the substance of these dimensions and form the component parts of scales we can use to measure position on these.

\section{MAPPING THE EUROPEAN POLICY SPACE}

Unlike our examples of the London Underground railway system, efforts to characterize the policy spaces in which political competition lack the luxury of known basis vectors in a known, "correct" number of dimensions. To illustrate this we now turn to a familiar political example: the much-debated nature of party competition in the European Union. Our focus is specifically on the dimensions of contestation at the transnational level, represented by the division of groups in the European Parliament.

\footnotetext{
${ }^{8}$ An equivalent plot generated by excluding the five variables identified in the last five columns of Table 2 is not much better.
} 
Our data comes from expert surveys of the positions of party groupings in the European Parliament conducted by McElroy and Benoit $(2011,2007)$ on 8 unique dimensions of policy. ${ }^{9}$ These groups along with their acronyms and seat shares are listed in Table 3.

\section{[TABLE 3 ABOUT HERE]}

The debate on the nature of party competition in the EU - the debate referenced by Gabel and Hix (2002) at the beginning of this paper - has occupied a great deal of attention in EU studies. The EP policy space has previously been described as onedimensional with the substance of the principal axis of competition being either the traditional left-right or 'regulation' dimension (Kreppel and Tsebelis, 1999; Tsebelis and Garrett, 2000) or geo-political pressures (Hoffman, 1966; Moravcsik, 1998). Other scholars, however, have described the European policy space as being spanned by two dimensions: a left-right dimension that bundles economic and socio-political issues from the domestic arena; and an orthogonal dimension contrasting the desires for EU integration and national sovereignty (Hix and Lord, 1997). As far as the transnational EU party policy space is concerned, therefore, there are several open questions: how many dimensions characterize party competition in the EU?; what is the content of these dimensions and how are these related?; where should we locate European party policy positions within the resulting "spaces"?

Expert surveys exemplify the a priori approach because the scales on which experts are asked to locate political parties must first be identified and clearly specified into a way that experts will find meaningful and relevant for locating parties. This choice is traditionally made by initially consulting experts in the political context

\footnotetext{
${ }^{9}$ These are: Taxes v. Spending; Deregulation; Social (liberalism); Environmental policy; EU Authority; Immigration; EU Federalism; EU Collective Security; Decentralization/Subsidiarity; and a general dimension of left-right whose interpretation was left to the experts. For full details see McElroy and Benoit (2007).
} 
being measured, and making careful choices as to which dimensions to specify and measure. For the European Parliament, for instance, the first expert survey taken by McElroy and Benoit (2007) did not include the dimension of decentralization/ subsidiarity ${ }^{10}$, but this was included in later surveys because it was judged ex ante to be relevant. This a priori feature is most explicit in the case of expert surveys, yet it features in some manner in every research design using indicators of distance between political agents - whether these indicators are categories for content analysis codings, identification of politically relevant texts or speeches, or the specification of survey items used to measure respondents' attitudes.

We start with the ubiquitous left-right dimension. Figure 6 plots expert survey estimates of the positions of the main EP party groups on the two main dimensions of difference identified by Benoit and Laver (2006) as a meaningful way to compare most political contexts: one contrasting an economic dimension of relative preferences of taxes versus spending, and another contrasting liberal with conservative social and moral attitudes. The configuration of party positions in this plot is almost "one-dimensional" in the sense that, of all the party groups, only the liberal ALDE lies in an off-diagonal position. The OLS regression line of best fit shown in the plot clearly indicates that (with one important exception) we can more or less predict the position on one dimension from the position on the other.

\section{[FIGURE 6 ABOUT HERE]}

If we then wish to consider the two dimensions to be manifestations of the same underlying dimension - call it "left-right" - then we can compare these directly with some of the other possible ways to measure left-right as a single dimension. What we

\footnotetext{
${ }^{10}$ The wording of this dimension was: "Decentralization/Subsidiarity: Insists on the subsidiarity principle in all administration and decision-making. (1) Accepts more centralized EU-level administration and decision-making. (20)"
} 
find from this exercise is that the ordering and placement of party groups on this single dimension varies according to the method used. Figure 7 contrasts three onedimensional "left-right" scales derived in different ways. The top dimension is derived from a unidimensional scaling of the economic and social positions shown in Figure 6. The model dimension is derived from the mean of the direct placements by the experts of party groups on the left-right scale. ${ }^{11}$ The bottom dimension is derived from the scores of each party group on the first dimension of a factor analysis of all expert placements on all dimensions except the overall left-right dimension. ${ }^{12}$

\section{[FIGURE 7 ABOUT HERE]}

Figure 7 shows that these placements are not consistent. We would have a very different picture of the far-right and anti-EU party group Europe of Freedom and Democracy (EFD), for instance, based on the unidimensional scale from the economic and social placements, versus the direct left-right placements, versus the third factor analytic scoring. The first scale fails to distinguish the more extreme anti-EU views of the EFD from those of the European Conservative and Reformist Group (ECR), while the third scale "wrongly" places the EFD in the middle of the "left-right" range. Of course, we are only supposing - following Gabel and Huber and host of others who have tried to interpret plots from roll call vote analysis (e.g. Hix Noury and Roland 2006) that the first principal component can be interpreted as a conventional "leftright" dimension. ${ }^{13}$ These same roll call analyses, however, suggest that distances

\footnotetext{
${ }^{11}$ The wording is: "Please locate each political group on a general left-right dimension, taking all aspects of group policy into account. Left (1). Right (20)."

${ }^{12}$ The observations were each expert's placement of each party on each dimension. Results are reported below in Table 3.

${ }^{13}$ Hix, Noury, and Roland (2006, 295):
}

We find one main dimension of politics in the European Parliament. This dimension is the classic left-right dimension of democratic politics. A second dimension is also present, although to a lesser extent. This dimension can be interpreted as the pro-/anti-Europe dimension...Our analysis is robust to the use of other scaling methods. 
between parties in the European Parliament require more than one dimension for an adequate spatial representation.

One substantive interpretation of a potential second dimension arises from "bipolar Euro-skepticism” (Marks et al 2006, 162) that manifests in a non-linear relationship between left-right positioning and support for further EU integration. Simply put, the EU is a project of mainstream and relatively centrist parties, while parties opposing European integration most tend to be on the extremes of the classical left-right scale (see also Hix and Lord, 1997; Marks, Wilson, and Ray, 2002). This gives rise to an inverted U-shaped configuration of party positions - although this depends once again on establishing the correct orientation - plotting general left-right positions against support for EU integration. This pattern is shown in Figure 8, which plots expert survey estimates of party positions on a general left-right scale against their positions on expanding or reducing the scope of EU Authority.

\section{[FIGURE 8 ABOUT HERE]}

Figure 8 plots two dimensions we assume a priori to be important in EU politics, and the results gives us a strong sense that we need more than a onedimensional map EU party positions. In an attempt to estimate this dimensionality inductively we could take estimated party positions on a wide range of issues and use a data reduction tool such as principal components factor analysis, to estimate how many, and which, latent dimensions are needed for an effective low-dimensional representation of the data. Table 4, which is analogous to Table 2, reports a PCA factor analysis with varimax rotated loadings from our analysis of all specific dimensional placements, except those from the overall left-right dimension. ${ }^{14}$ Based on conventional interpretations, this is a "two-factor" solution explaining two-thirds

\footnotetext{
${ }^{14}$ The correlation of the scored factors with left-right placements are about .67 and .33 respectively.
} 
of the variation in placements - a result that would please most analysts. We also see that the first factor seems to consist of domestic policy issues while the second dimension consists mainly of transnational issues: the scope of EU authority, collective security, issues of national sovereignty surrounding the creation of more federal EU institutions, and the related issue of subsidiarity and the decentralization of decision-making. It would be quite reasonable, given these results, to interpret the first factor as a "left-right" dimension and the second dimension in terms of attitudes to "EU integration". Such an interpretation would be completely consistent with most empirical work on the topic (e.g. others, McElroy and Benoit 2007) and thoroughly in line with our theoretical expectations.

\section{[TABLE 4 ABOUT HERE]}

For a distance matrix of unknown dimensionality, multi-dimensional scaling would be the most common inductive method for "mapping" the positions of the parties - used in roll-call vote analysis, text scaling, or just plain vanilla multidimensional scaling from survey responses or other indicators. Indeed, if the distance matrix corresponded to physical locations as in our London Tube example - and assuming we know the correct orientation and number of dimensions - then we could easily turn this set of distances into a "map". This is exactly what we have done and plotted in Figure 9. Echoing the results of the factor analysis, the two-dimensional solution also emerges very robustly from multi-dimensional scaling. ${ }^{15}$ The relative locations of the parties, however, compared with those from our descriptive mapping

\footnotetext{
${ }^{15}$ Here we used positioning by each expert of each party group as inputs to a classical MDS, with variables consisting of every policy dimension except overall left-right. From 106 observations, we retained two dimensions explaining $43.7 \%$ and $21.6 \%$ of the variance respectively. To produce the locations in Figure 11, we took the party group mean dimensional scores as the positions reported in Figure 11, and inverted the first dimension. Our experiments with dropping various dimensional inputs showed that the scaling was extremely robust, yielding essentially the same placements when single dimensions or pairs of dimensions were left out as variables.
} 
in Figure 8 based on direct locations by experts, shows a number of key differences.

The inductive map's “wrong” placements include:

- the extremist EFD is located in a more moderate position on the left-right scale than somewhat less extremist ECR;

- $\mathrm{Gr} / \mathrm{EFA}$ is placed as more extreme than the in fact quite extreme GUE/NGL on the left-right scale;

- the two "Green" (GR/EFA and GUE/NGL) party groups are identified as more Euro-skeptic than the ECR and EFD, both groups for which Euro-skepticism is a core element of their identity;

- $\mathrm{Gr} / \mathrm{EFA}$ is located as extremely Euro-skeptic when it should be more moderately pro-EU;

- the extremist GUE/NGL is given the same left-right position as the centreright ALDE, a location with which no expert would ever agree; and

- the EPP becomes the most pro-EU party, another highly implausible interpretation of the party groups' policies.

In addition to these misplacements from the inductive scaling, there is also the orientation of the inductive map: in producing Figure 9 we had to invert the positions of the left-right dimension, since these were "clearly" flipped in the locations based on what we "knew" about the extreme parties. This knowledge was, strictly speaking, external to the scaling process. Distance cannot tell the whole story, and may produce a "mapping" of the policy space that - like our attempts to generate the Circle Line map inductively - may be very different from other possibly more accurate and useful representations.

\section{[FIGURE 9 ABOUT HERE]}

\section{CONCLUDING REMARKS AND RECOMMENDATIONS}

Scholars use low-dimensional conceptual maps of political spaces as parsimonious and useful ways to represent a huge amount of information about political preferences and, hopefully, to screen out confusing and/or irrelevant detail. There is no such thing 
as the "one true" conceptual map of any given political setting, waiting to be discovered if only we could find it. Just as real maps are spanned by dimensions, conceptual maps are spanned by conceptual dimensions, which we use to provide substantive orientation. Just as there is not one "true" map, neither is there one "true dimensionality" for any given political setting. Sometimes, as with London's Central line, a one-dimensional map will tell us everything we want to know. Sometimes, as with London's Circle line, it will not. Nearly always, we ignore potentially salient dimensions in the name of a parsimonious description of the world, just as we typically do not seek three-dimensional maps of London tube stations - despite the fact that these stations do in fact have substantively meaningful geographic coordinates in three dimensions. ${ }^{16}$

Most maps of the physical world are based on strong a priori assumptions about the number and nature of the dimensions we use to interpret them. As we have seen, we also often have strong a priori assumptions about the number and nature of dimensions spanning useful conceptual maps of the political world. If we can indeed make such assumptions, the job of mapping is made much easier. It becomes a matter of locating the unknown positions of key political agents on known policy dimensions. This is a relatively well-understood exercise in one-dimensional scaling. If, however, we insist on leaving the number and nature of the basis vectors of our conceptual space as completely open questions, then we face a much more difficult, and arguably impossible, task. In essence, our estimation problem is left with too many degrees of freedom. Furthermore, a posteriori orientation and interpretation of spaces estimated using no a priori assumption about dimensionality will, in our view inevitably, make reference to a priori policy dimensions, such as left-right or liberal-

\footnotetext{
${ }^{16}$ And, indeed, if we want to know how long it will take to exit any given tube station, knowing how deep it is underground will give us quite useful information.
} 
conservative, that have emerged as part of the commonly understood language of political discourse. Our strong recommendation is to leverage our de facto knowledge of these dimensions as part of the estimation process rather than assuming, at the start of the investigation, that the space we are estimating many have any conceivable dimensionality and the dimensions we derive might have any conceivable substantive meaning. 


\section{References}

Adams, James F., Samuel Merrill, and Bernard Grofman. 2005. A Unified Theory of Party Competition: A Cross-National Analysis Integrating Spatial and Behavioral Factors. Cambridge: Cambridge University Press.

Austen-Smith, David, and Jeffrey S. Banks. 2000. Positive Political Theory I: Collective Preference. Ann Arbor: University of Michigan Press.

- - - 2005. Positive Political Theory II: Strategy and Structure. Ann Arbor: University of Michigan Press.

Converse, Phillip E. 1964. "The nature of belief systems in mass publics." In Ideology and Discontent. , ed. D. E. Apter. London: Free Press of Glencoe.

Gärdenfors, Peter. 2000. Conceptual spaces : the geometry of thought. Cambridge, Mass.: MIT Press.

Schofield, Norman. 2008. The Spatial Model of Politics. London: Routledge.

Carlyle, Thomas. 1871. The French Revolution: A History. 3 vols. Vol. 1. London: Chapman and Hall, 1871.

Hix, S. and C. Lord. 1997. Political Parties in the European Union. Basingstoke: Macmillan.

Gabel, Matt and Simon Hix. 2004. "Defining the EU Policy Space: an empirical study of the European election manifestos, 1979-1999.” In Gary Marks, Marco R. Steenbergen eds., European integration and political conflict. Cambridge University Press.

Hix, Simon, Abdul Noury, and Gerard Roland. 2006. "Dimensions of Politics in the European Parliament" American Journal of Political Science 50(2, April): 494-511.

Hoffman, S. (1966) 'Obstinate or Obsolete? The Fate of the Nation State and the Case of Western Europe', Daedalus 95: 862-915.

Moravcsik, A. (1998) The Choice for Europe, Social Purpose and State Power from Messina to Maastricht. Ithaca, NY: Cornell University Press.

Kreppel, A. and G. Tsebelis (1999) 'Coalition Formation in the European Parliament', Comparative Political Studies 32: 933-66.

Tsebelis, G. and G. Garrett (2000) 'Legislative Politics in the European Union', European Union Politics 1: 9-36.

Lakoff, George and Mark Johnson. 1980. "Conceptual Metaphor in Everyday Language.” Journal of Philosophy 77(8): 453-486. 
Marks, Gary and Marco Steenbergen. 2002. "Understanding Political Contestation in the European Union." Comparative Political Studies 35(8): 879-892.

McElroy and Benoit 2007. "Party Groups and Policy Positions in the European Parliament." Party Politics 13(1): 5-28.

Pennings, Paul. 2002. "The Dimensionality of the EU Policy Space : The European Elections of 1999." European Union Politics 3(59).

Selck, Torsten J. 2004. "On the Dimensionality of European Union Legislative Decision-Making." Journal of Theoretical Politics April 2004 vol. 16 no. 2 203-222

Warwick, Paul V. 2002. "Toward a Common Dimensionality in West European Policy Spaces.” Party Politics 8: 101. 


\begin{tabular}{cccc}
\hline $\begin{array}{c}\text { Noisy } \\
\text { indicator of } \\
\text { easting }\end{array}$ & $\begin{array}{c}\text { Cronbach's } \\
\text { alpha for easting } \\
\text { indicators }\end{array}$ & $\begin{array}{c}\text { Noisy } \\
\text { indicator of } \\
\text { northing }\end{array}$ & $\begin{array}{c}\text { Cronbach's } \\
\text { alpha for } \\
\text { northing } \\
\text { indicators }\end{array}$ \\
\hline \hline East0 & 0.904 & North0 & 0.912 \\
East1 & 0.897 & North1 & 0.908 \\
East2 & 0.904 & North2 & 0.902 \\
East3 & 0.899 & North3 & 0.895 \\
East4 & 0.905 & North4 & 0.898 \\
East5 & 0.896 & North5 & 0.912 \\
East6 & 0.899 & North6 & 0.895 \\
East7 & 0.910 & North7 & 0.895 \\
East8 & 0.900 & North8 & 0.901 \\
East9 & 0.898 & North9 & 0.910 \\
\hline East scale & & North scale & \\
Cronbach's alpha & 0.910 & Cronbach's alpha & 0.912 \\
East scale & & North scale & \\
correlation with & 0.966 & correlation with & 0.959 \\
"real” easting & & real" northing & \\
\hline
\end{tabular}

Table 1: Diagnostics of additive east-east and north-south scales built from noisy indicator variables 


\begin{tabular}{lrr}
\hline Input & Factor1 & Factor2 \\
\hline \hline east0 & $\mathbf{0 . 8 6}$ & 0.20 \\
east1 & $\mathbf{0 . 6 2}$ & -0.02 \\
east2 & $\mathbf{0 . 5 6}$ & -0.09 \\
east3 & $\mathbf{0 . 6 7}$ & 0.18 \\
east4 & $\mathbf{0 . 7 8}$ & 0.19 \\
north0 & 0.40 & $\mathbf{0 . 6 2}$ \\
north1 & 0.16 & $\mathbf{0 . 5 9}$ \\
north2 & 0.38 & $\mathbf{0 . 5 3}$ \\
north3 & -0.09 & $\mathbf{0 . 6 8}$ \\
north4 & 0.22 & $\mathbf{0 . 6 5}$ \\
dateopen & 0.50 & -0.38 \\
npass2008 & 0.41 & -0.29 \\
pctirish & 0.22 & $\mathbf{0 . 5 3}$ \\
nplatforms & 0.25 & -0.27 \\
farezone & -0.50 & -0.15 \\
\hline
\end{tabular}

Table 2: Rotated Principal Components factor loadings for observations of Central Line Tube stations 


\begin{tabular}{lcrr} 
EP Party Group & Label & Seat \% & Seats \\
\hline \hline European People's Party & EPP & 36.0 & 265 \\
Party of the European Socialists/Socialists and Democrats & PES/S\&D & 24.9 & 183 \\
Alliance of Liberals and Democrats for Europe & ALDE & 11.6 & 85 \\
European United Left/Nordic Green Left & GUE/NGL & 4.8 & 35 \\
Greens/European Free Alliance & Verts/EFA & 7.5 & 55 \\
Europe of Freedom and Democracy & EFD & 4.1 & 30 \\
European Conservative and Reformist Group & ECR & 7.3 & 54 \\
Non Affiliated & NI & 3.8 & 28 \\
$\quad$ & & 100 & 735 \\
\hline
\end{tabular}

Table 3. Political Party Groups in European Parliament in 2010. Source: European Parliament official website 


\begin{tabular}{lrrr}
\hline Factor & & Eigenvalue & $\begin{array}{r}\text { Cumulative } \\
\text { Proportion }\end{array}$ \\
\hline \hline $\mathbf{1}$ & 4.02 & 0.45 \\
$\mathbf{2}$ & 1.93 & 0.66 \\
3 & 0.88 & 0.76 \\
& 4 & 0.69 & 0.84 \\
5 & 0.58 & 0.90 \\
6 & 0.40 & 0.94 \\
7 & 0.23 & 0.97 \\
8 & 0.14 & 0.99 \\
9 & 0.12 & 1.00
\end{tabular}

Rotated Factor Loadings

\begin{tabular}{lrr} 
& $\mathbf{1}$ & $\mathbf{2}$ \\
Taxes v. & & \\
Spending & $\mathbf{0 . 8 4}$ & 0.02 \\
Deregulation & $\mathbf{0 . 8 0}$ & 0.15 \\
Environment & $\mathbf{0 . 8 2}$ & 0.05 \\
Social Liberalism & $\mathbf{0 . 7 4}$ & 0.37 \\
Immigration & $\mathbf{0 . 6 7}$ & $\mathbf{0 . 4 8}$ \\
Decentralization & 0.34 & $\mathbf{- 0 . 6 1}$ \\
EU Security & 0.08 & $\mathbf{0 . 6 9}$ \\
EU Federalism & 0.28 & $\mathbf{0 . 8 5}$ \\
EU Authority & 0.17 & $\mathbf{0 . 8 6}$ \\
& & \\
$N$ & & 106 \\
\hline
\end{tabular}

Table 4. Inductively derived "dimensionality" of the EP Policy Space 


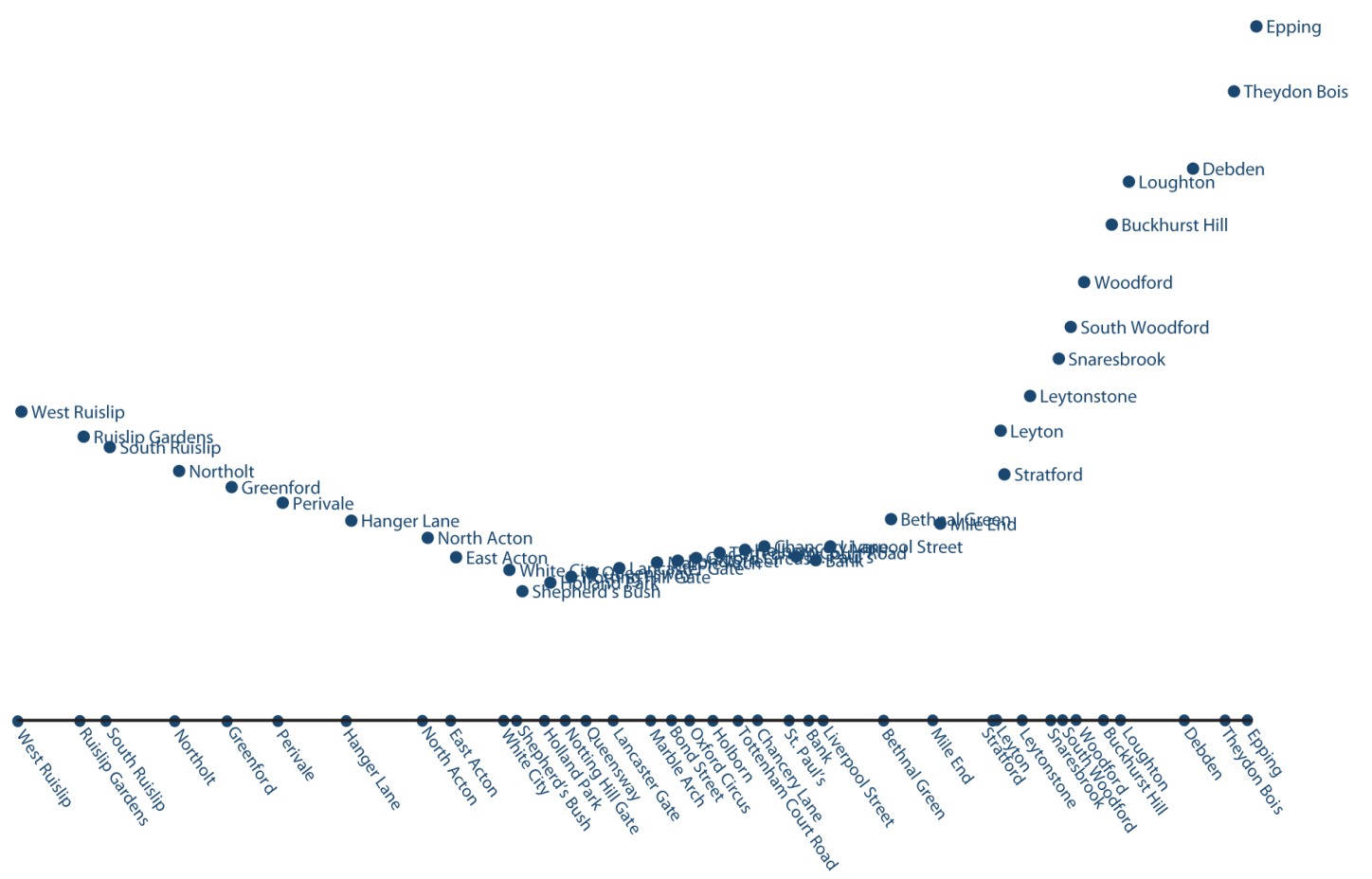

Figure 1: Locations of Central Line stations on the London Underground

Top panel: Two-dimensional geographically accurate plot

Bottom panel: One-dimensional plot consistent with Beck's stylized Tube map 

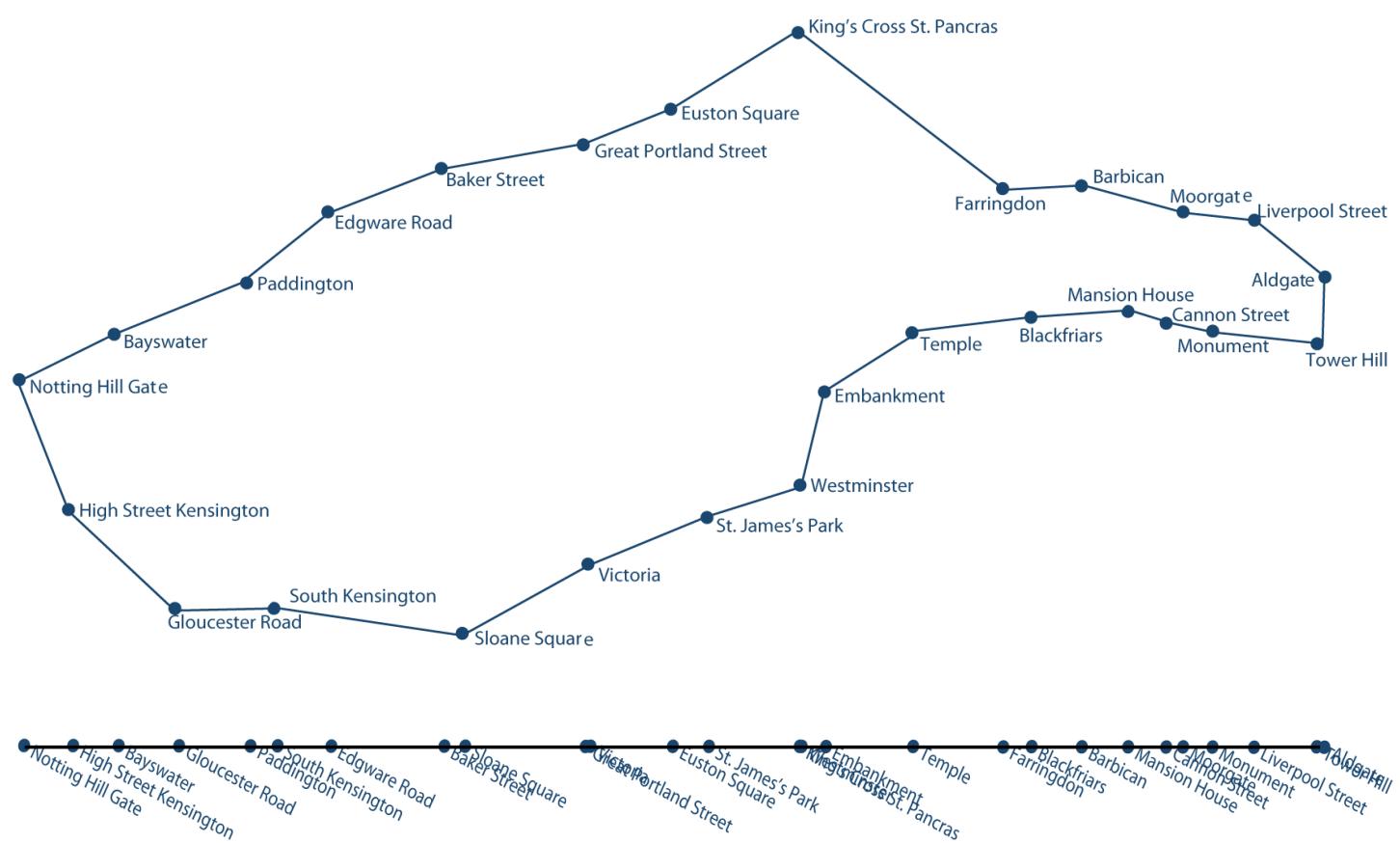

Figure 2: Locations of Circle Line stations on the London Underground Two-dimensional (top panel) and one-dimensional (bottom panel) geographically accurate plots 

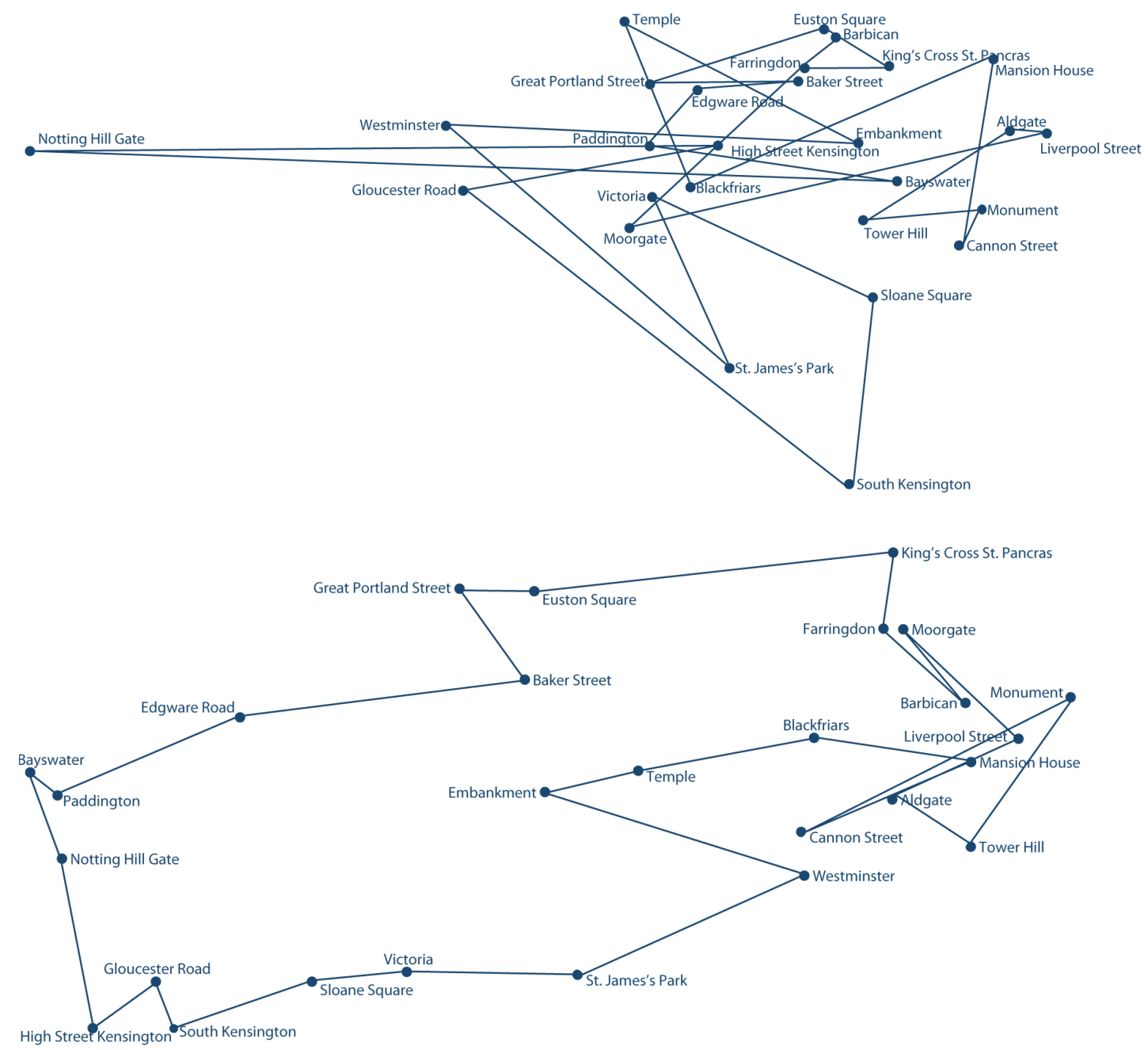

Figure 3: Plot of east3 vs north3 (top panel) and eastscale vs northscale (bottom panel) 


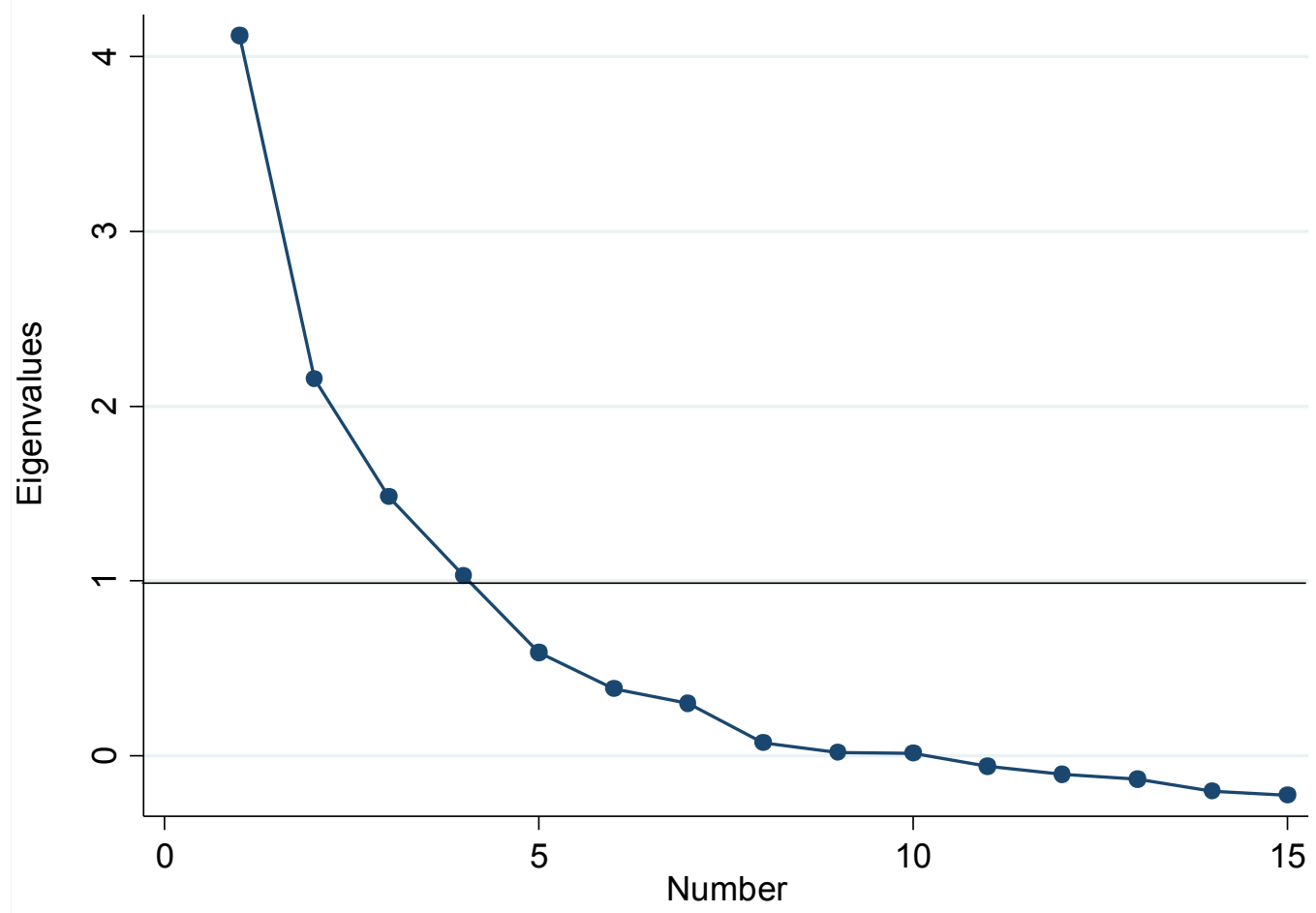

Figure 4: Scree plot of eigenvalues arising from factor analysis of noise data on London tube station locations 


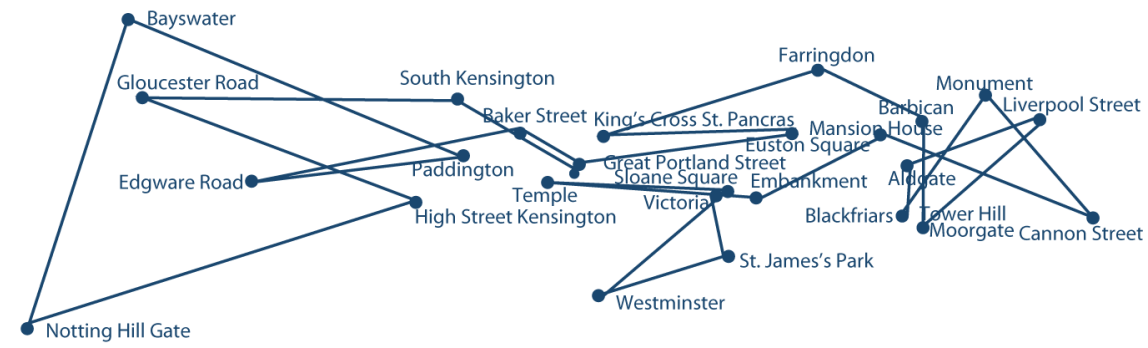

Figure 5: Two-dimensional MDS plot of Circle Line stations 


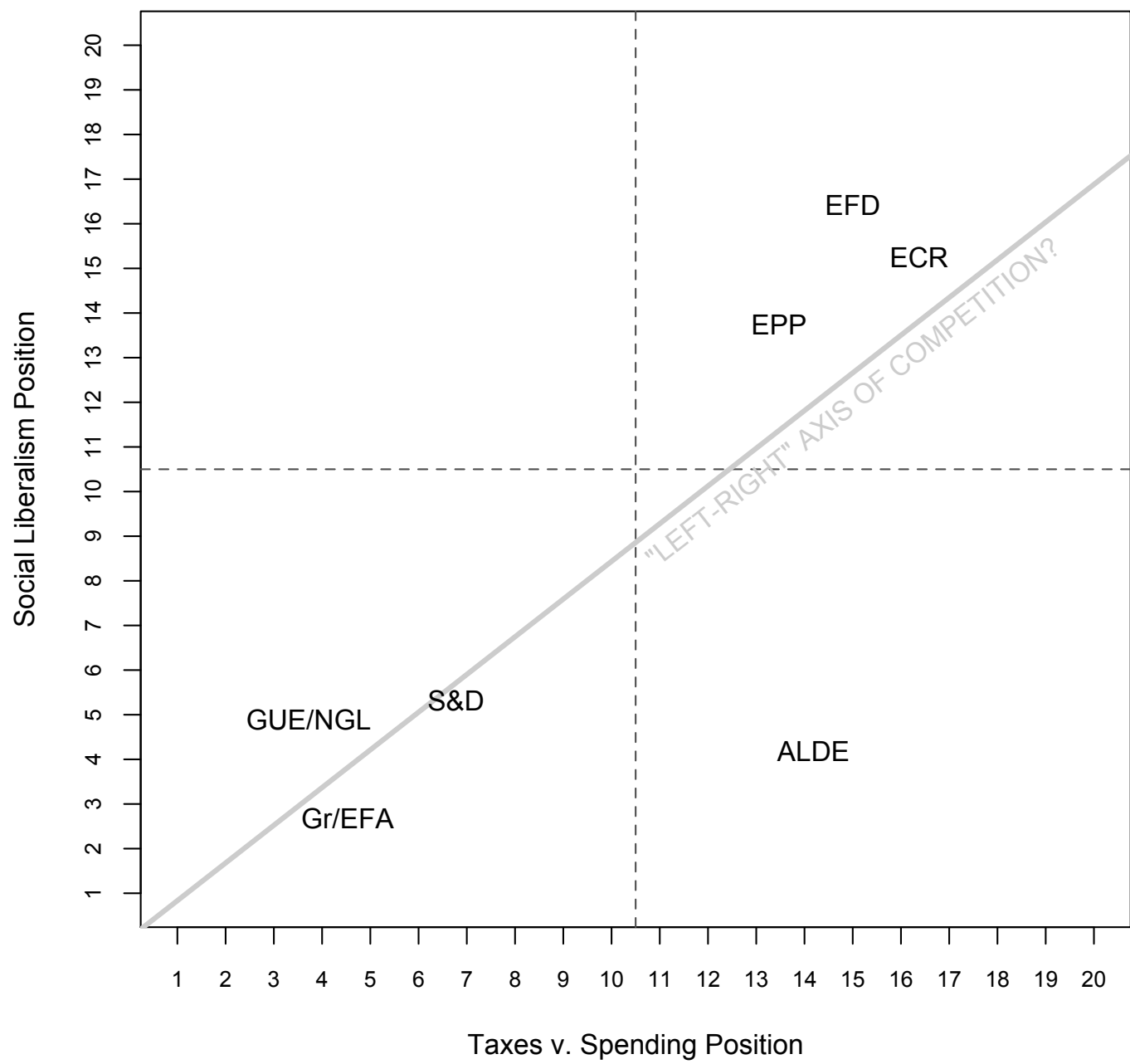

Figure 6. Descriptive mapping of the Economic v. Social Positions of the European Party Groups, 2010. 

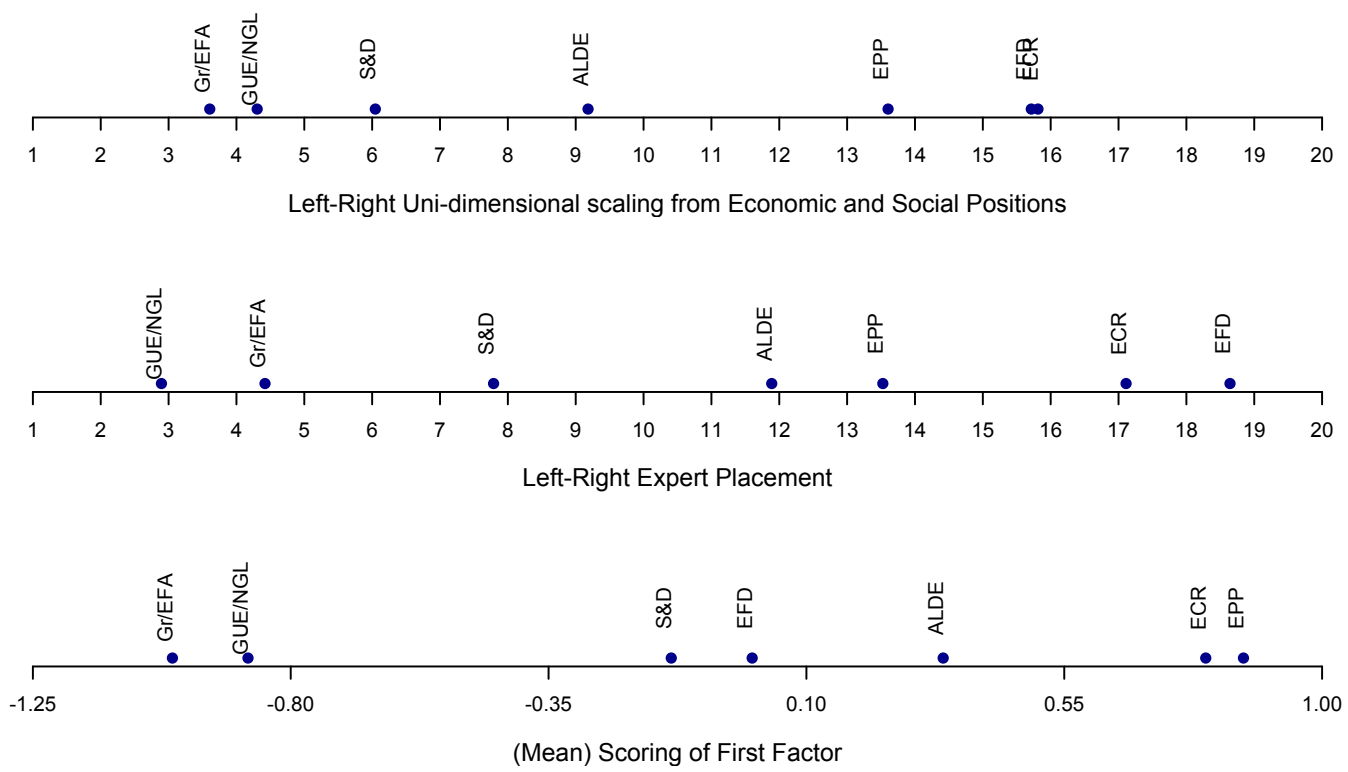

Figure 7. Three Uni-dimensional Scale Positions of "Left-Right". 


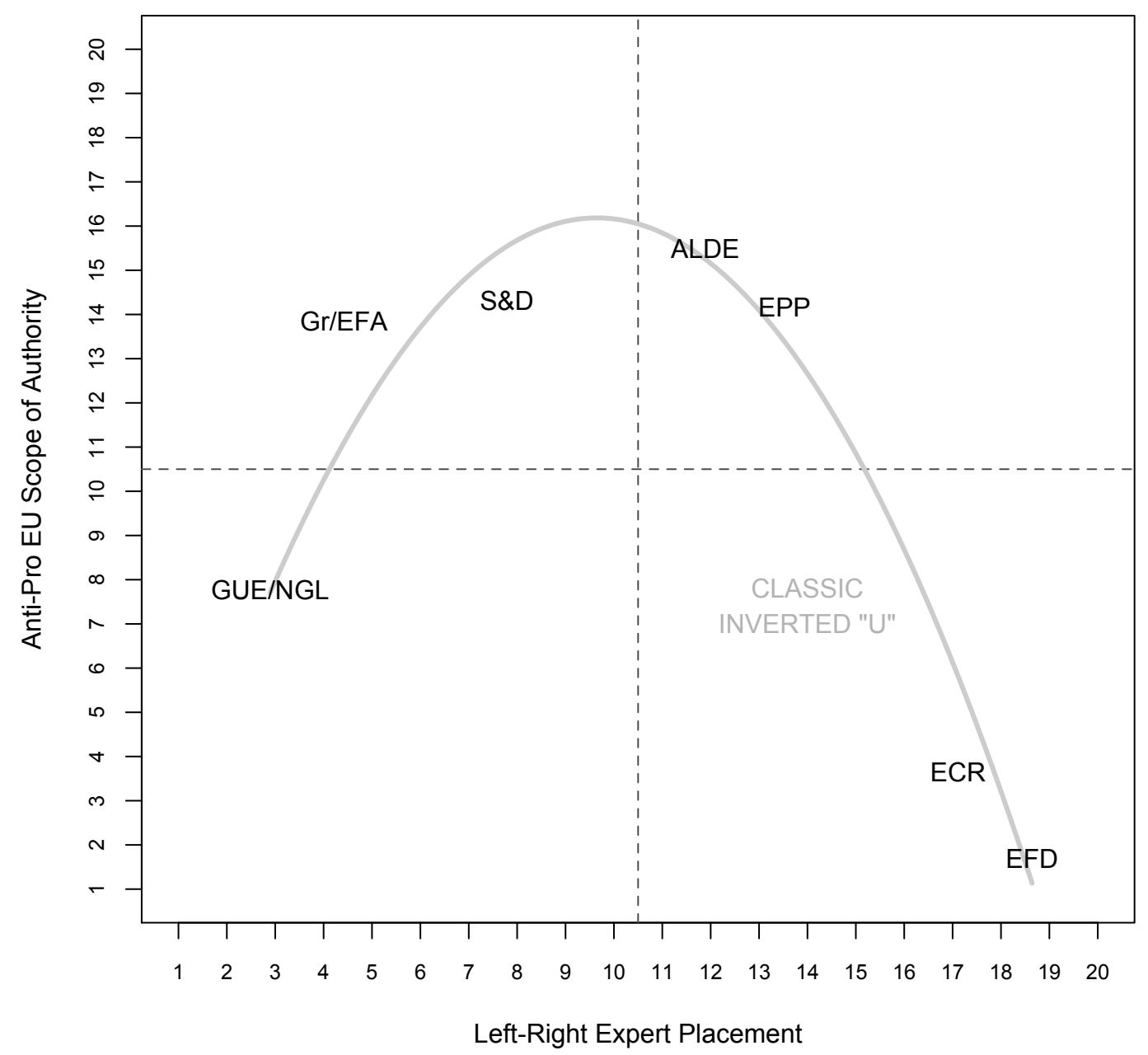

Figure 8. Descriptive mapping of the Expert Left-Right Placements Against Anti- v. Pro-EU Authority. Curved line is a quadratic fit weighted by seat share. 


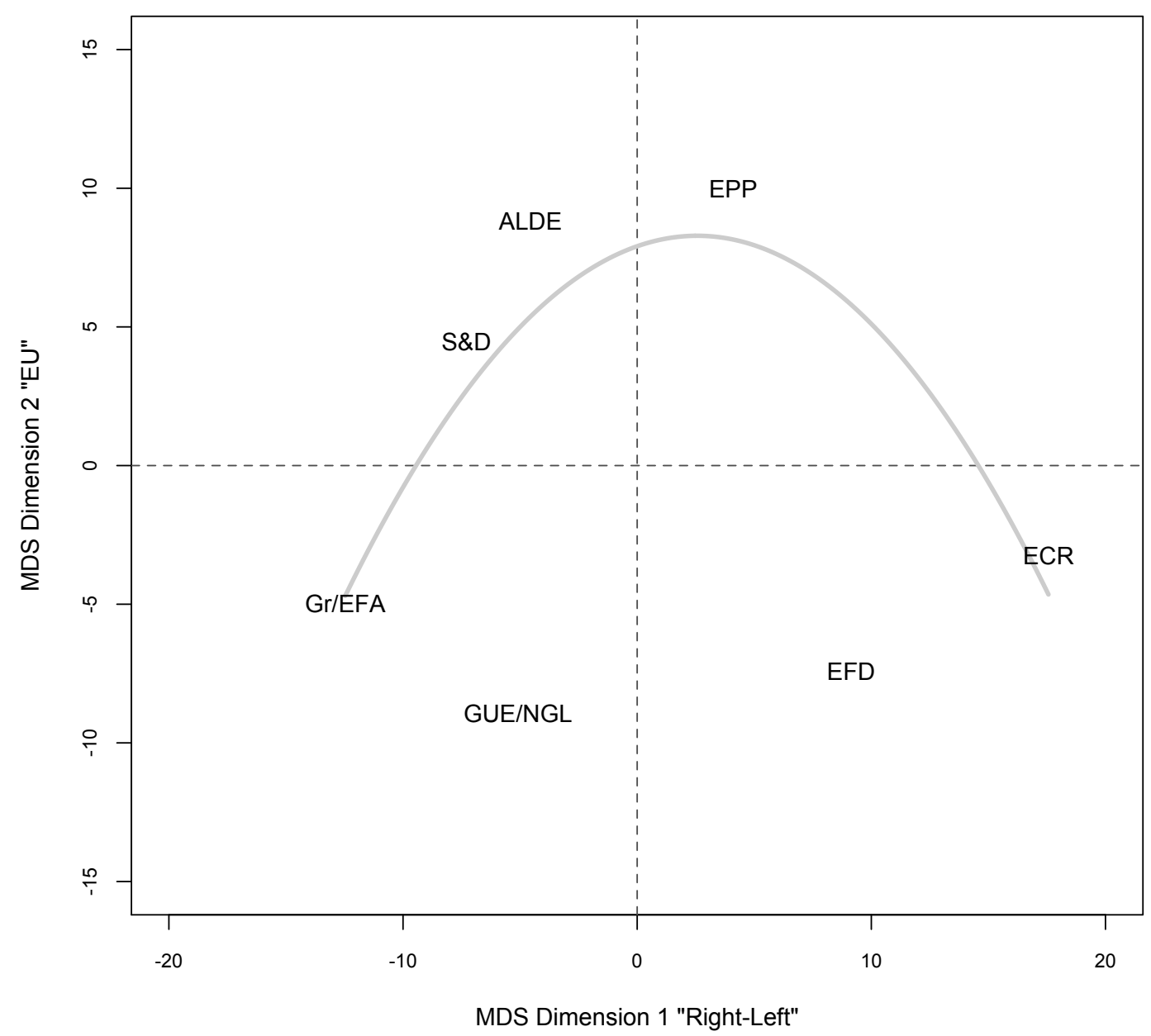

Figure 9. Inductive mapping of the Left-Right Positioning Against Anti-v. Pro-EU Authority. Curved line is a quadratic fit weighted by seat share. Results are from a classical MDS fit of expert placements of all party groups on all dimensions (except overall left-right). 